\title{
MEMBANGUN KESADARAN DINI MASYARAKAT DALAM MEMBANGUN DESA TANGGUH BENCANA DI DUSUN KADIROJO PALBAPANG BANTUL
}

\author{
BUILDING EARLY AWARENESS COMMUNITY IN DEVELOPING \\ DISASTER RESILIENT VILLAGEIN KADIROJO PALBAPANG BANTUL
}

\author{
${ }^{1}$ Ratih Herningtyas, ${ }^{2}$ Surwandono \\ ${ }^{1,2)}$ Program Studi Ilmu Hubungan Internasional \\ Fakultas Ilmu Sosial dan Ilmu Politik, Universitas Muhammadiyah Yogyakarta \\ JL. Brawijaya, Tamantirto, Bantul Yogyakarta 55183 \\ Email: ratih_herningtyas@umy.ac.id
}

\begin{abstract}
ABSTRAK
Dusun Kadirojo Palpabang Bantul merupakan wilayah yang mengalami kerusakan masif dan jumlah kematian yang besar pada saat terjadi gempa bumi 27 Mei 2006. Wilayah ini memiliki posisi geologis yang terlewati oleh sesar gempa bumi dan hanya empat km dari pusat gempa di Sungai Opak. Mempertimbangkan potensi akan terjadinya bencana dimasa akan datang, diperlukandaya tahan masyarakat di daerah rawan bencana. Mitra kegiatan ini adalah organisasi Muhammadiyah di tingkat desa atau ranting, yaitu organisasi yang memiliki kontribusi besar dalam gerak kehidupan sosial, ekonomi dan keagamaan, dan memiliki potensi besar sebagai agen sosial dan perubahan dalam masyarakat. Tujuan kegiatan ini adalah untuk meningkatkan kesadaran diri pengurus Pimpinan Ranting Muhammadiyah (PRM) Kadirojo Palpabang Bantul sebagai agen sosial dalam membangun desa tangguh bencana melalui desiminasi seperangkat gagasan dan pendampingan dalam membangun desa tangguh bencana. Metode pengabdian masyarakat ini menggunakan pendekatan konstruktivis dari Peter L Berger, melalui 2 aktivitas utama, yaitu obyektifikasi dalam bentuk penyusunan buku panduan bergambar tentang tata kelola pembangunan desa tangguh bencana dan eksternalisasi dalam bentuk focus group discussion. Hasil kegiatan ini menunjukkan adanya peningkatan kesadaran diri pengurus PRM Kadirojo Palbapang Bantul yang ditunjukkan melalui pengukuran skala pengetahuan, nilai dan tindakan dalam membangun desa tangguh bencana dan hal ini berguna untuk mengelola isu bencana secara produktif.
\end{abstract}

Kata kunci: Desa Tangguh Bencana; Kesadaran Dini; Kadirojo

\begin{abstract}
Kadirojo village in Palpabang Bantul is a region that suffered massive damages and a large number of deaths during the earthquake of May 27, 2006. This region has a geological position that was surpassed by an earthquake fault and only four $\mathrm{km}$ from the epicenter of the Opak River. Considering the potential for future disasters, it needs to develop the resilience of communities in disaster-prone areas. Muhammadiyah organization is an organization that has a significant contribution in social, economic, and religious movement and has excellent potential as a social agent and change in society. This activity aims to encourage and increase the awareness of Muhammadiyah activists in Kadirojo Palpabang Bantul as social agents in developing disaster resilient villages. The method used in this activity is based on the constructivist approach from Peter L. Berger, through 2 main events. First, writing guide books on governance for disaster resilient village development. Second, externalization by conducting focus group discussions. The results of this activity showed that there was an increasingawareness of the Muhammadiyah Branch Leader Kadirojo Palbapang, Bantul, which was demonstrated through the measurement of the scale of knowledge, values and actions in developing disaster resilient villages.
\end{abstract}

Keywords: Disaster Resilient Village; Early Awareness; Kadirojo

Submitted : 15 Oktober 2019 Revision : 1 Desember 2019 Accepted : 17 Februari 2020 


\section{PENDAHULUAN}

Desa Palbapang, Kecamatan Bantul Yogyakarta, merupakan salah satu desa yang mengalami kerusakan yang massif pada saat terjadi gempa bumi 27 Mei 2006. Merujuk data dari kantor desa Palbapang, bencana gempa bumi tersebut menyebabkan lebih dari $80 \%$ bangunan privat dan publik mengalami kerusakan parah, dan menelan korban jiwa meninggal dunia sampai 40 orang, dan ratusan di antaranya mengalami luka berat dan ringan yang memerlukan perawatan di rumah sakit (Kompas, 2017). Dalam peristiwa gempa di tahun 2006, jarak antara pusat gempa ke desa Palbapang hanya berjarak $4 \mathrm{~km}$ dari episentrum gempa, dengan kedalaman gempa hanya $10 \mathrm{~km}$. Desa Palbapang Bantulsecara posisi geologis berada dalam garis merah sesar yang kemudian mengalami hentakan gempa susulan secara terus menerus. Banyak rumah penduduk yang sebelumnya belum mengalami rusak parah pada waktu gempa utama, kemudian mengalami kerusakan sedang dan akhirnya menjadi rusak berat. Kondisi ini menyebabkan sejumlah fasilitas publik dan privat mengalami kerusakan yang parah.Hal ini mendorong sejumlah organisasi dunia seperti IOM (International Organzation on Migration) bersama dengan FAO (Food and Agriculture Organization) membangun sejumlah depo logistik di sekitar kawasan desa Palbapang. Bahkan konsorsium rekonstruksi seperti JRF (Java Reconstruction Funds), IRF (Islamic Releif) dan Pertamina menjadikan desa Palbapang sebaga salah satu desa yang mendapatkan prioritas pertama untuk pembangunan kembali sejumlah aset publik seperti Sekolah Dasar Kadirojo, Sekolah Dasar Karasan, Sekolah Dasar Serut, maupun sejumlah Puskesmas Palbapang, dan sejumlah rumah penduduk yang hancur akibat gempa (Herningtyas \& Surwandono, 2013).

Pasca terjadinya gempa bumi tersebut, terdapat gejala munculnya sejumlah persoalan. Pertama, problem kesiapan mental masyarakat dalam menghadapi bencana secara massif. Gempa bumi 2006 meluluhlantakan sejumlah bangunan, namun yang paling kritikal adalah juga hancurnya sumber-sumber air bersih. Selama seminggu pertama terjadi kekurangan stok air bersih yang memadai, dan stok pangan. Akibatnya guratan keputusasaan sedemikian rupa sangat tampak, yang kemudian menimbulkan sikap emosional dan agresif, sehingga seperti daerah bencana di Indonesia pada umumnya, masa kritis di awal bencana ditandai dengan sejumlah penjarahan dan penghadangan terhadap distribusi bantuan dari luar (James, 2008). Kedua, problem kebencanaan juga muncul dalam proses menghadapi kebencanaan yang panjang. Rumah yang hancur, lapangan kerja yang hilang, dan sederet masalah yang menghantui. Perbincangan paling sering yang dilakukan oleh sejumlah organisasi masyarakat yang mendapat keluhan dari masyarakat adalah pilihan kebijakan untuk melakukan "penjualan kenestapaan (suffering), tangisan (crying) kepada fihak ketiga agar empati memberikan bantuan kemanusiaan (Herningtyas \& Surwandono, 2017). Organisasi sosial menjadi sangat tidak elegan dalam membangun komunikasi dengan pihak lain, karena seakan hanya ada satu pilihan saja agar mendapatkan bantuan dengan segera. Dengan menjual ratapan dan tangisan, seakan menjadi satusatunya pilihan yang paling baik dalam konteks bencana agar mendapatkan bantuan.Dalam konteks bencana di dunia ketiga, fenomena banalitas media dengan menjual ratapan dan tangisan untuk mendapatkan bantuan adalah sesuatu yang jamak. Namun juga harus dimengerti bahwa pilihan ini harus diubah dengan membangun komunikasi yang lebih baik kepada pihak lain. Pihak pemberi bantuan sesungguhnya bukanlah minta ditempatkan sebagai Malaikat atau bahkan Tuhan, yang harus dipuja-puja dengan tangisan dan air mata. Namun sudah menjadi sebuah narasi besar, proses mengkomunikasikan fenomena bencana dengan informasi dramatis, bahkan sampai menjadi berita hoaks. Berkembangnya berita hoak dalam penginformasian bencana menimbulkan sejumlah kepanikan, ketidakpercayaan, bahkan tindakan agresif. Kondisi ini kemudian berpengaruh terhadap sejumlah keputusan tentang kebencanaan menjadi tidak tepat sasaran. Dalam kasus bencana di Palbapang, pemerintah daerah kabupaten Bantul akhirnya untuk menghindari kompleksnya persepsi korban terhadap bantuan yang akan diterima, memilih dengan semangat "dumdil" atau dibagi secara adil secara merata (Reid Basher, 2013). Untuk konteks ini, adil dalam makna kuantitatif, di mana siapa saja 
yang jadi korban bencana akan mendapatkan besaran yang sama, tidak memadang apakah dari status sosial kaya atau miskin, namun hanya dengan menggunakan indikator tunggal sebagai sesama korban bencana. Ketiga, proses rekonstruksi dan rehabilitasi meninggalkan sejumlah masalah akut terkait dengan tata kelola kerjasama dari pihak-pihak yang memberikan bantuan (Herningtyas \& Surwandono, 2010). Masalah yang paling menonjol adalah tidak jelasnya mekanisme kerjasama secara kelembagaan yang kemudian disinyalir menjadi penyebab utama terjadi peristiwa korupsi bantuan bencana. Sejumlah tokoh formal seperti kepala dusun, perangkat desa kemudian diadukan oleh warga masyarakat korban bencana, dengan delik korupsi (Yamamura, 2014). Kondisi ini menjadi masalah krusial, di mana distribusi bantuan pendanaan yang memerlukan waktu yang lama, bahkan mencapai kurun waktu 3 tahun dari peristiwa bencana. Sejumlah tokoh sentral yang selama ini menjadi penghubung yang ditetapkan menjadi tersangka dan harus menjalani proses persidangan. Peristiwa ini memicu sejumlah tokoh formal dan informal memilih untuk tidak menjadi mediator ataupun konektor bantuan kebencanaan, sehingga menyebabkan sejumlah bantuan yang dijadwalkan cair pada periode 2 tahun pasca bencana kemudian tidak cair. Persoalanpersoalan ini berpotensi akan muncul kembali jika masyarakat maupun para pihak yang terlibat dalam isu bencana tidak disiapkan untuk menjadi masyarakat yang tangguh bencana yaitu masyarakat yang memiliki kemampuan untuk menghadapi bencana dengan menguatkan kapasitas dan potensi dari diri dan lingkungannya sendiri.

Muhammadiyah selama ini menjadi organisasi sosial yang melakukan pendampingan masyarakat secara intensif di desa Palbapang Bantul. Hal ini tercermin dengan sejumlah kegiatan rutin berupa pengajian, yang berbasis mingguan, bulanan, maupun selapanan (35 hari), maupun kegiatan bakti sosial di masyarakat. Namun demikian, untuk menjadikan PRM memiliki kapasitas yang unggul dalam pengelolaan desa tangguh bencana perlu diperkuat lebih jauh. Hal ini terkait dengan fenomena kebencanaan yang melahirkan sejumlah anomali perilaku masyarakat. Seperangkat pengetahuan etis kebencanaan, kemampuan komunikasi kebencanaan dan membangun kemitraan untuk proses rekonstruksi dan rehabilitasi secara transparan dan profesional menjadi kebutuhan yang sangat penting (Hesselman \& Lane, 2017). Inilah tantangan baru yang dihadapi oleh PRM di seluruh Indonesia. Muhammadiyah tidak hanya berkutat kepada pengelolaan isu pendidikan dan kesehatan yang telah menjadi trade mark amal usaha Muhammadiyah. Namun juga harus terlibat secara aktif dalam melakukan pendampingan membangun desa tangguh bencana agar menghasilkan gagasangagasan yang konstruktif dalam masyarakat, dan tetap mampu membangun dan menjunjung ukhuwah Islamiyyah (persaudaraan islam) dan wathoniyah (persaudaraan kebangsaan). Program pengabdian ini telah melakukan pendampingan secara sistematis terhadap PRM agar menjadi pilar sosial baru dalam membangun desa tanggung bencana.

\section{METODE}

Pelaksanaan pengabdian kepada masyarakat ini menggunakan pendekatan pelembagaan dari Peter L Berger tentang konstruktivisme (Berger \& Luckmann, 2016), dengan sasaran atau mitra kegiatan utama adalah para pengurus PRM Kadirojo Palbapang yang berjumlah 20 orang dan semuanya adalah laki-laki. Mereka adalah warga Kadirojo yang selama ini aktif menggerakkan kegiatankegiatan PRM dan memiliki pengalaman menjadi korban bencana gempa 2006.

Kegiatan ini dilakukanmelalui 2 aktivitas utama, yaitu obyektifikasi dalam bentuk penyusunan buku panduan bergambar tentang tata kelola membangun desa tangguh bencana, daneksternalisasi dalam bentuk focus group discussion (FGD) secara berseri bagi pengurus PRM. Kedua aktivitas dilakukan secara kolektif dan interaktif, dan mendesiminasikan modul tata kelola pengelolaan desa tangguh bencana yang guna meningkatkan kapasitas masyarakat dalam mengelola isu kebencanaan secara positif dan produktif.

Langkah dan tahapan dalam melakukan kegiatan ini dimulai dengan pertama, melakukan penyusunan Buku Panduan 
Bergambar tentang membangun desa tangguh bencana, dengan mendasarkan pada buku Diplomasi Bencana: Sejarah, Peluang dan Kerjasama, dan Fiqh Kebencanaan yang dikeluarkan oleh Pimpinan Pusat Muhammadiyah. Buku panduan membangun desa tangguh bencana dibangun melalui penguatan etis melalui internalisasi nilai dalam fiqh kebencanaan, penguatan komunikatif dalam mengkomunikasikan fenomena kebencanaan secara efektif dan efisien, dan membangun jaringan kerjasama dengan lembaga pemerintah dan lembaga sosial yang memiliki tugas pokok dan fungsi dalam kebencanaan. Langkah pertama ini merupakan bagian dari proses obyektivikasi sebagaimana pandangan dari Peter L Berger. Obyektifikasi merupakan proses untuk mengetahui secara persis terhadap gejala sosial yang berkembang, dan termasuk di antaranya alternatif solusi yang relevan dengan masalah tersebut (Berger \& Luckmann, 2016). Pembuatan buku adalah upaya untuk membuat masalah dan solusi dapat menyatu dan mudah untuk dikomunikasikan (Berger \& Luckmann, 2016). Pilihan untuk membuat buku panduan membangun desa tangguh dengan gambar, didasarkan pada pertimbangan untuk mempermudah pemahaman dari masyarakat dan pengurus ranting Muhammadiyah. Gambar akan lebih memberikan ruang untuk diingat dibandingkan dengan tulisan yang panjang dan mendetil. Gambar juga akan memberikan pesan lebih tentang interpretasi sesuatu.

Kedua, melakukan $F G D$ secara sistematis. $F G D$ dilakukan sebanyak 2 kali. Sebelum pelaksanaan FGD, peserta akan diberikan assessment awal sebagai bagian dari Pre-Test untuk mengetahui pengetahuan awal dari partisipan terkait dengan persepsi dalam memandang bencana, mengkomunikasikan bencana, dan membangun jaringan dan kerjasama untuk mengatasi problem kebencanaan. Pelaksanaan FGD merupakan bagian dari proses eksternalisasi, yakni tentang bagaimana proses subjective relativity dan objective relativity dapat bertemu. Antara tim pengabdian dan masyarakat yang menjadi target pengabdian dapat melakukan sharing gagasan untuk melakukan pendalaman lebih jauh tentang bagaimana membangun mental positif dalam memaknai bencana. Untuk menjamin agar FGD dapat berjalan dengan efektif maka akan menggunakan pendekatan partisipatif, di mana relasi antara masyarakat dan pengabdi adalah setara. Kedua belah fihak memiliki keunggulan masing-masing yang dapat dibagi dan dirumuskan secara komprehensif

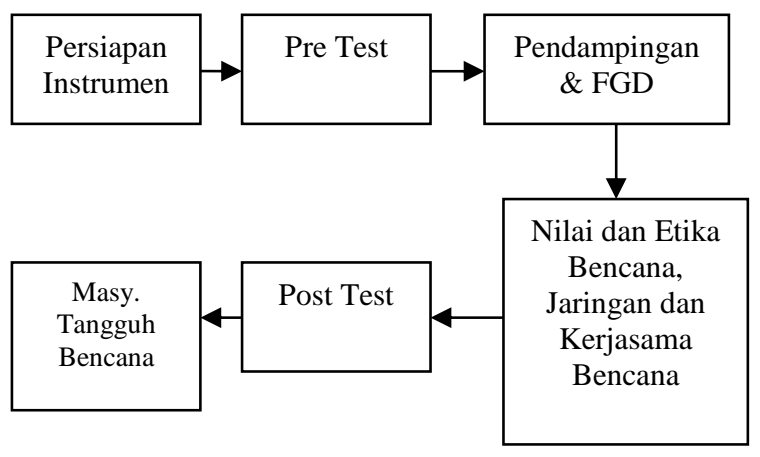

Gambar 1. Alur Focus Group Discussion

Pre-Test akan memandu fasilitator untuk dapat menjalankan peran secara efektif dan efisien dalam menyampaikan pesan-pesan penting, dan menyerap aspirasi dari para peserta. Sedangkan tahap post test, merupakan langkah akhir untuk mengevaluasi sejauh mana keterserapan pengetahuan, sikap, dan nilai yang telah disampaikan dalam pelaksanaan FGD oleh partisipan.Instrumen pre test dan post test, disusun dengan menggunakan variable yang terdapat dalam regulasi pembangunan desa tangguh, dan sejumlah dokumen desa tangguh dari sejumlah negara. Instrumen ini kemudian diklasifikasikan dalam 3 variabel besar, yakni pertama, struktur pengetahuan tentang desa tanggung bencana. Kedua tentang tata nilai tentang desa tanggung bencana dan ketiga tentang tindakan yang dilakukan dalam membangun desa tangguh bencana.

\section{HASIL DAN PEMBAHASAN}

Dalam pelaksanaan program pengabdian, penyusunan buku panduan bergambar telah dilakukan dan digunakan dalam kegiatan tahap kedua yaitu FGD. Pelaksanaan FGD dilakukan oleh dua orang fasilitator yang masing-masing memiliki peran dan tugas masing-masing. Fasilitator pertama menyampaikan materi seputar pengalaman membangun desa tanggung di sejumlah Negara, dengan menayangkan film dokumenter tentang 
kebencanaan di Jepang, dan film tentang pembuatan desa tangguh di Jepang. Sedangkan fasilitator kedua menyampaikan materi seputar regulasi desa tangguh bencana, dan bagaimana mensikapi kebencanaan dalam pandangan Islam.

Fasilitator pertama menyampaikan gambaran dengan pola-pola masyarakat dalam menghadapi kebencanaan, sedang masyarakat tersebut tinggal di daerah rawan bencana. Pilihan ada dua, meninggalkan lokasi tempat tinggal secara permanen, dengan mencari lahan baru yang tidak memiliki riwayat kebencanaan yang tinggi, atau yang kedua, tetap tinggal di lokasi tenpat tinggal, meski memiliki kerentanan kebencanaan, namun mempersiapkan diri secara lebih baik. Sejumlah peserta berpandangan bahwa pilihan yang kedua adalah pilihan yang paling rasional dan tepat terkait dengan posisi masyarakat Kadirojo. Apalagi mereka mengaku memiliki ikatan emosional, akar budaya dan tradisi yang melekat dalam kehidupan di wilayah lama, dan sulit jika harusmemulai membangunnya di tempat yang baru. Ada nilai-nilai lokal yang membantu mereka bertahan hidup termasuk dalam situasi bencana. Hal tersebut dapat menjadi aset dalam membangun masyarakat tangguh bencana (Kusumasari \& Alam, 2012).

Jepang menjadi contoh bagaimana hidup di dalam wilayah yang memiliki kerentanan bencana dan bagaimana masyarakat Jepang mengelola kerawanan daerah bencana dengan mempergunakan tehnologi. Ketangguhan merupakan aktivitas yang perlu diusahakan. Manusia dikaruniai akal dan fikiran, dapat mengelola permasalahan dan kesulitan, untuk kemudian menjadi pembelajaran untuk tumbuh, dewasa dan tangguh. Paparan video tersebut kemudian memantik sejumlah diskusi intensif tentang bagaimana masyarakat Kadirojo dalam mengelola kerawananan akibat bencana gempa bumi dengan membangun struktur rumah tahan gempa. Termasuk di dalamnya, perlu dibuat taskforce yang dapat mengelola ketangguhan bencana dengan melibatkan anggota masyarakat yang lebih luas (Kusumasari, 2012). Dalam FGD ini, juga dilakukan Pre-test dan Post-test sebelum dan setelah FGD dilaksanakan. Hasil dari pre test dan post test menunjukkan hasil postif. Ada perubahan skala Pengetahuan, Nilai, dan
Tindakan dalam membangun desa tangguh bencana. Hasilnya dapat dilihat seperti dalam Tabel I berikut ini :

Table 1. Rekap Hasil Pre test dan Post Test

\begin{tabular}{|c|c|c|c|c|c|c|}
\hline \multirow{2}{*}{ No } & \multicolumn{2}{|c|}{ Pengetahuan } & \multicolumn{2}{c|}{ Nilai } & \multicolumn{2}{c|}{ Tindakan } \\
\cline { 2 - 7 } & Pre & Post & Pre & Post & Pre & Post \\
\hline 1 & 2 & 1.7 & 3 & 3.2 & 3 & 1.7 \\
\hline 2 & 2.5 & 1.7 & 3.4 & 2.8 & 2.1 & 1.7 \\
\hline 3 & 2.9 & 2.3 & 2.7 & 3.4 & 2.1 & 2.3 \\
\hline 4 & 2.1 & 2.9 & 4 & 3 & 2.9 & 2.9 \\
\hline 5 & 2.1 & 2.9 & 3.8 & 3.5 & 3 & 2.9 \\
\hline 6 & 2.1 & 2.2 & 3.3 & 3 & 3.4 & 2.2 \\
\hline 7 & 2 & 2.1 & 3 & 3.4 & 3 & 2.1 \\
\hline 8 & 1.8 & 2.4 & 2 & 3.5 & 1.3 & 2.4 \\
\hline 9 & 2 & 2.2 & 2.7 & 3.4 & 0.6 & 2.2 \\
\hline 10 & 2 & 4 & 2.9 & 4 & 1.8 & 4 \\
\hline 11 & 1.9 & 3 & 3.4 & 3.1 & 2.1 & 3 \\
\hline 12 & 2 & 3 & 3 & 3 & 2.4 & 3 \\
\hline 13 & 2.1 & 3.1 & 3.3 & 3.8 & 1.5 & 3.1 \\
\hline 14 & 2.2 & 2.3 & 2.9 & 3.8 & 3 & 2.3 \\
\hline & 29.7 & 35.8 & 43.4 & 46.9 & 32.2 & 35.8 \\
\hline M & 2.12 & 2.55 & 3.1 & 3.35 & 2.3 & 2.56 \\
\hline
\end{tabular}

Dalam konteks rata-rata pengetahuan tentang desa tangguh mengalami kenaikan dari 2.12 ke 2.5. Meskipun dalam konteks skala, penambahan skor pengetahuan tetap belum masuk ke dalam kluster Tahu yakni dengan indeks 3. Belum signifikannya perubahan pengetahuan terkait dengan masih sangat kurangnya pengetahuan tentang desa tangguh bencana. Semua peserta menyatakan bahwa baru pertama kali ini mendengar tentang desa tangguh bencana. Bahkan ketika oleh fasilitator dikejar dengan pertanyaan apakah tidak pernah ada forum di desa terkait dengan issue membangun desa tangguh bencana? Semua audiens menyatakan bahwa tidak pernah ada pembahasan tentang desa tangguh bencana. Bahkan ketika dikejar dengan pertanyaan, desa Kadirojo terletak tidak jauh dari sekretariat operasional BPBD (Badan Penanggulangan Bencana Daerah) Bantul, semua audiens kembali menegaskan tentang kurangnya sosialisasi dari unsur pemerintah maupun lembaga kemanusiaan kebencanaaan. Networking antara Pemerintah termasuk BPBD dan masyarakat merupakan aset penting dalam membangun desa tangguh bencana (Kusumasari, 2012).

Dalam konteks internalisasi nilai desa tangguh, dari score 3.1 meningkat menjadi 3.35. Score ini mewakili bahwa masyarakat 
sudah memiliki nilai yang tangguh dan kuat dalam menghadapi bencana. Hal ini dapat dimaklumi, bahwa sebagian besar yang hadir adalah tokoh organisasi, dan sekaligus para tokoh keagamaan di lingkungan masyarakat Palbapang. Intervensi pengabdian tetap memberikan kontribusi dalam penanamaman nilia tentang arti penting menghadapi bencana secara positif.

Masyarakat Kadirojo dan PRM Kadirojo (Palbapang Barat) merupakan salah satu pilot project "Qoryah Thoyyibah" atau "masyarakat percontohan" dalam menjalankan praktik hidup Islami ala Muhammadiyah. Derajat religuisitas masyarakat Kadirojo berhubungan positif dengan cara pandangan masyarakat dalam menghadapi bencana. Gagasan tentang desa tangguh bencana seakan memperkuat keyakinan bahwa dibalik sebuah musibah kebencanaan harus direspon dengan positif, agar manusia menjadi lebih tangguh, dan melakukan instropeksi dalam proses konservasi alam.

Sedangkan dalam konteks tindakan untuk membangun desa tangguh bencana, intervensi pengabdian juga mampu memotivasi masyarakat untuk mengambil inisiatif lebih, meskipun hasilnya memang belum maksimal. Ada perubahan motivasi dari 2.3 menjadi 2.53. Perubahan ini masih dalam level agak siap, belum benar-benar siap. Kondisi ini tidak bisa dilepaskan dari kurangnya pendampingan dalam melakukan pelatihan desa tangguh bencana, baik yang dilakukan oleh pemerintah maupun organisasi kemanusiaan kebencanaan. Para peserta dalam merespon kebencanaan masih bersifat reaksioner dan individual. Dalam arti reaksioner, tidak ada persiapan yang sistematis dan serius dalam menghadapi kebencanaan. Bencana masih diterima apa ada, belum dihadapi dengan persiapan yang memadai dan terukur. Sedangkan dalam arti individual, tindakan menghadapi kebencanaan masih menjadi aktivitas individual dalam belum menjadi program kolektif dalam masyarakat seperti dalam lingkungan Rukun Tetangga (RT), Rukun Warga (RW), Kampung, Desa atau bahkan dalam Jamaah Pengajian dan Masjid.

Dari hasil FGD tersebut, tercermin bahwa intervensi pembangunan desa tangguh harus dilakukan lebih sistematis dan simultan. Sistematis dalam arti dilakukan secara berkesinambungan, terprogram, dan teranggarkan. Sedangkan simultan, proses intervensi membangun desa tangguh dilakukan oleh banyak fihak secara serentak dan terintegrasi. Dibutuhkan keterpaduan gerakan desa tangguh bencana antara peguruan tinggi, pemerintah dan lembaga kebencanaan, organisasi sipil kebencanaan, maupun lembaga kemanusian.

\section{SIMPULAN}

Pembangunan desa tangguh bencana memerlukan keterlibatan antar stakeholder kebencanaan. Pemerintah memiliki tanggung jawab yang luas untuk mensosialisasikan regulasi desa tangguh bencana secara sistematis kepada masyarakat yang tinggal di daerah rawan bencana. Pembuatan peta rawan bencana dan peta desa tangguh bencana menjadi sebuah keniscayaan, dan dikelola dengan sistematis. Keterpaduan antara berbagai fihak dalam membangun desa tangguh bencana menjadi salah satu kunci untuk mempercepat pertumbuhan desa tangguh bencana di daerah rawan bencana. Keterpaduan ini akan mampu meningkatkan pengetahuan, nilai, dan tindakan tangguh bencana dari masyarakat, yang kemudian pada akhirnya akan menciptakan desa tangguh bencana.

\section{UCAPAN TERIMA KASIH}

Program pengabdian masyarakat ini merupakan program hibah pengabdian dengan skema Program Kemitraan Masyarakat. Tim pengabdian mengucapkan terima kasih kepada LP3M UMY yang telah memberikan dana bagi pelaksanaan program ini, Pimpinan Ranting Muhammadiyah Kadirojo Palbapang Bantul Yogyakarta sebagai mitra yang telah membantu koordinasi dan pelaksanaan program, dan seluruh pihak di dusun Kadirojo sebagai mitra bagi pelaksanaan kegiataan ini atas partisipasi aktif dan kerjasamanya.

\section{DAFTAR PUSTAKA}

Berger, P., \& Luckmann, T. (2016). The social construction of reality. Social Theory ReWired: New Connections to Classical and Contemporary Perspectives: Second Edition, 110-122. https://doi.org/10.4324/9781315775357 
Herningtyas, R., \& Surwandono. (2010). Diplomasi Bencana Alam sebagai Saran Meningkatkan Kerjasama Internasional. Jurnal Hubungan Internasional, UMY, 3(2), 181-188.

Herningtyas, R., \& Surwandono. (2013). Indonesia's Diplomacy In Disaster Issue: How To Capitalize Disaster As Soft Diplomacy, Yogyakarta, Universitas Muhammadiyah Yogyakarta. In The First Postgraduate Research Conference Improving Human Life. Yogyakarta: Universitas Muhammadiyah Yogyakarta.

Herningtyas, R., \& Surwandono. (2017). Diplomasi Bencana: Sejarah, Peluang, Kerjasama Internasional. Yogyakarta: CV Komojoyo.

Hesselman, M., \& Lane, L. (2017). Disasters and non-state actors - human rights-based approaches. Disaster Prevention and Management: An International Journal, 26(5), 526-539. https://doi.org/10.1108/DPM-07-20170174

James, E. (2008). Getting ahead of the next disaster: Recent preparedness efforts in Indonesia. Development in Practice, 18(3), 424-429. https://doi.org/10.1080/09614520802030 607
Kompas. (2017, May 27). Mengingat Kembali Gempa Yogyakarta 11 Tahun Lalu. Kompas. Retrieved from https://regional.kompas.com/read/2017/0 5/27/13193441/mengingat.kembali.gemp a.yogyakarta.11.tahun.lalu?page=all

Kusumasari, B. (2012). Network organisation in supporting post-disaster management in Indonesia. International Journal of Emergency Services, 1(1), 71-85. https://doi.org/10.1108/20470891211239 326

Kusumasari, B., \& Alam, Q. (2012). Local wisdom-based disaster recovery model in Indonesia. Disaster Prevention and Management: An International Journal, 21(3), 351-369. https://doi.org/10.1108/09653561211234 525

Reid Basher. (2013). Disaster Impacts : Implications and Policy Responses. Social Research, 75(3), 937-954.

Yamamura, E. (2014). Impact of natural disaster on public sector corruption. Public Choice, 161(3-4), 385-405. https://doi.org/10.1007/s11127-0140154-6 